\title{
Synthesis of Alicyclic 2-Methylenethiazolo[2,3-b]quinazolinone Derivatives via Base-Promoted Cascade Reactions
}

\author{
Mohamed El Haimer ${ }^{\mathrm{a}}$ \\ Tünde Faragóa \\ Zsuzsanna Schelz ${ }^{b}$ \\ István Zupkób \\ Márta Palkó*a (ic \\ a Institute of Pharmaceutical Chemistry, University of Szeged, \\ Interdisciplinary Excellence Centre, Eötvös utca 6, Szeged \\ 6720, Hungary \\ palko.marta@szte.hu \\ b Pharmacodynamics and Biopharmacy, University of Szeged, \\ Interdisciplinary Excellence Centre, Eötvös utca 6, Szeged \\ 6720 , Hungary \\ Dedicated to the memory of Professor Ferenc Fülöp. \\ Published as part of the Special Issue dedicated to Prof. Ferenc Fülöp
}
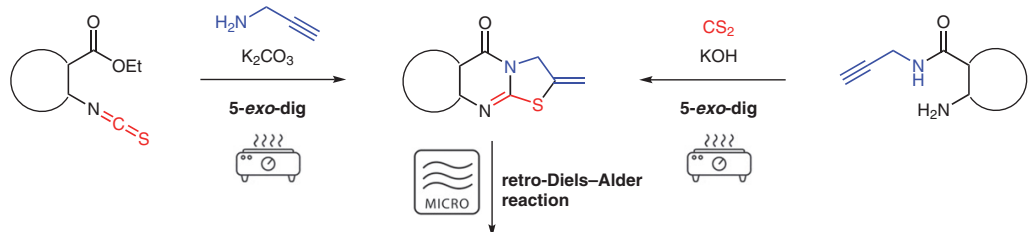

\section{retro-Diels-Alde} reaction

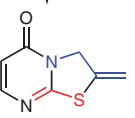

Received: 15.10.2021

Accepted after revision: 29.10.2021

Published online: 07.12 .2021

DOI: 10.1055/s-0040-1720028; Art ID: ss-2021-t0623-st

Abstract The synthesis of alicyclic 2-methylenethiazolo[2,3-b]quinazolinones is performed via base-promoted cascade reactions, starting from either alicyclic $\beta$-amino propargylamides using carbon disulfide, or from alicyclic ethyl 2-isothiocyanatocarboxylates by addition of propargylamine. In both cases the cascade reaction proceeds by way of a favoured 5-exo-dig process during the second ring closure, as confirmed by full NMR spectroscopic assignments. Moreover, a high-yielding retro-Diels-Alder (RDA) reaction is performed on the norbornene derivatives leading to 2-methylene-2H-thiazolo[3,2-a]pyrimidin-5(3H)-ones. The obtained compounds exert modest antiproliferative activities against a panel of human gynaecological cancer cell lines.

Key words 2-methylenethiazolo[2,3-b]quinazolinones, propargylamine, fused quinazolinones, domino ring closure, 5-exo-dig

Quinazoline heterocycles are important subunits of a broad variety of natural products as well as synthetic pharmaceuticals possessing antiviral, ${ }^{1}$ anti-inflammatory, ${ }^{2,3}$ antimalarial $^{4}$ and anticancer ${ }^{5}$ activities. Their synthesis and modification have played a significant role in aspects of both organic and pharmaceutical chemistry throughout the years, resulting in the generation of various derivatives, ranging from simple substituted molecules to more complex fused systems. Lately, thioquinazoline derivatives, with a thio group at the $\mathrm{C} 2$ position of the quinazoline moiety, have received increasing attention. ${ }^{6}$ This is because of their potential biological activities, such as antimicrobial, ${ }^{7}$ antivi$\mathrm{ral}^{8}{ }^{8}$ antitumor, ${ }^{9-11}$ and the treatment of Parkinson's disease. ${ }^{12,13}$ Moreover, nitrogen- and sulfur-containing heterocycles, such as thiazolidines, exist in diverse pharmaceutical compounds and drugs, and they are frequently found in many biologically active natural products. ${ }^{14}$ Due to their attractive and privileged position in medicinal chemistry, the synthesis of functionalised thiazolidines has been the focus of several recent publications. ${ }^{15}$

At this juncture, the development of compounds containing a thiazolo[2,3-b]quinazolinone core has attracted increasing attention in pharmaceutical sciences. Numerous synthetic procedures towards thiazolo[2,3-b]quinazolinones have been reported in the literature, including classic cyclisation reactions of thioquinazoline derivatives with various $\gamma$-substituted allyl halides, ${ }^{16}$ 1,2-dielectrophiles, ${ }^{17}$ and so on. Even transition-metal-catalysed protocols have been developed for the synthesis of this specific core. ${ }^{18} \mathrm{Un}$ fortunately, these procedures suffer from several drawbacks, such as tedious multiple-step processes, limited scope, and often poor yields.

In recent years, two protocols have been published for the syntheses of 2-methylene-substituted thiazolo[2,3-b]quinazolinone derivatives that proceed via a tandem bicyclisation strategy. In the first report, a cyclisation reaction between ortho-amino- $\mathrm{N}$-(prop-2-yn-1-yl) aromatic amides and carbon disulfide was developed in the presence of potassium hydroxide, followed by a favoured 5-exo-dig ring closure ${ }^{19}$ The second protocol involved a cascade bicyclisation reaction of ortho-alkenylphenyl isothiocyanates with propargylamines. ${ }^{20}$

Although the biological properties of thiazolo[2,3-b]quinazolinones have stimulated the development of a large number of synthetic methods to construct and decorate this moiety, there are fewer synthetic approaches towards the corresponding cyclic and alicyclic derivatives. Hence, in conjunction with our ongoing research on the study and modification of alicyclic $\beta$-amino propargylamide deriva- 
tives through domino reaction procedures, ${ }^{21,22}$ our present work is directed towards the syntheses of alicyclic 2-methylene-substituted thiazolo[2,3-b]quinazolinones. The synthetic process involves base-promoted cascade reactions of alicyclic $\beta$-amino propargylamides or alicyclic ethyl 2 -isothiocyanatocarboxylates, followed by investigations on retro-Diels-Alder (RDA) reactions of the norbornene derivatives.

First, alicyclic $N$-Boc-protected propargylamides $\mathbf{1 b}-\mathbf{8 b}$ were prepared in yields of $72-84 \%$ by following a previously described procedure. ${ }^{21,22}$ This involved addition of a mixture of $N, N^{\prime}$-diisopropylcarbodiimide (DIC) and hydroxybenzotriazole $(\mathrm{HOBt})$ to the corresponding Boc-protected amino acids 1a-8a in tetrahydrofuran, followed by the addition of propargylamine (Scheme 1). On the other hand, according to the literature, ${ }^{23-25}$ several alicyclic ethyl-2-isothiocyanatocarboxylates $(\mathbf{9 b}-\mathbf{1 8 b})$ were obtained in relatively high yields from the corresponding 2-amino esters (9a-18a) upon reaction with thiophosgene (Scheme 2).

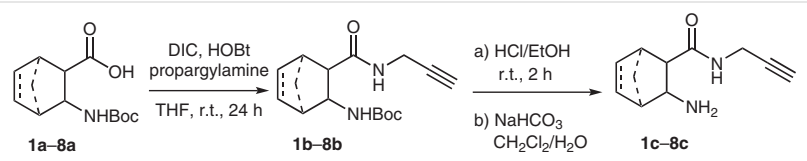<smiles>C#CCNC(=O)C1(C(=O)NCC#CCNC(=O)C2(N)CC=CCC2N)CC#CCC1N</smiles>

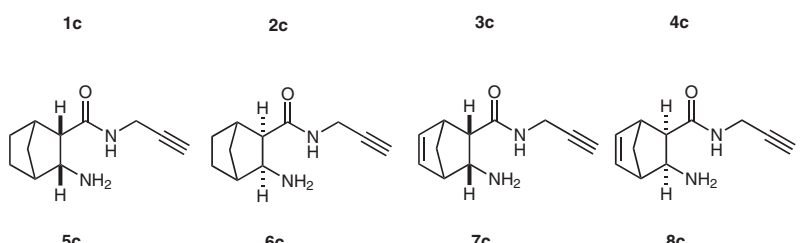
$5 c$ $6 c$

$7 c$

$8 c$

Scheme 1 Synthesis of N-Boc-protected propargylamides $\mathbf{1 b}-\mathbf{8 b}$

Alicyclic $N$-Boc-protected propargylamides $\mathbf{1 b}-\mathbf{8 b}$ were deprotected to give free amide bases $\mathbf{1 c - 8 c}$, which were used without any further purification (Scheme 1). These alicyclic amino propargylamides were then reacted with carbon disulfide in ethanol in the presence of one equivalent of potassium hydroxide. The reaction proceeded through a two-step cascade process starting with the formation of isothiocyanate $\mathbf{A}$, which was followed by the first ring closure to give 2-thioxo-2,3-dihydroquinazolinone intermediate B. Finally, a favoured 5-exo-dig ring closure took place leading to the desired alicyclic 2-methylene-substituted thiazolo[2,3-b]quinazolinones 19-26 (Scheme 3).

Despite the possibility of the formation of two different products, that is, 5-exo-dig and 6-endo-dig compounds, this straightforward reaction step showed regioselectivity in the second ring closure step, leading only to 5-exo-dig ring products. The results showed a noticeable increase in the yield of the final product aligned with a decrease in the
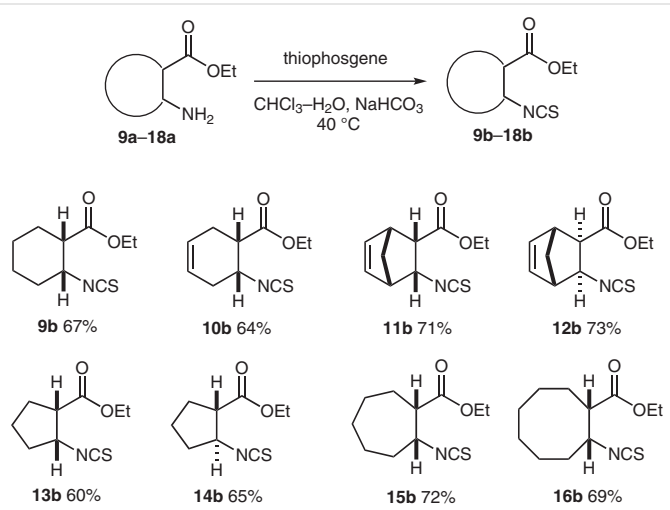<smiles>CCOC(=O)C1CCC=CCCC1([N+](=O)[O-])[N+](=O)[O-]</smiles>

17b $73 \%$

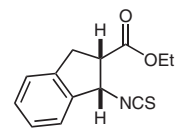

18b $69 \%$

Scheme 2 Synthesis of alicyclic ester isothiocyanates $\mathbf{9 b - 1 8 b}$
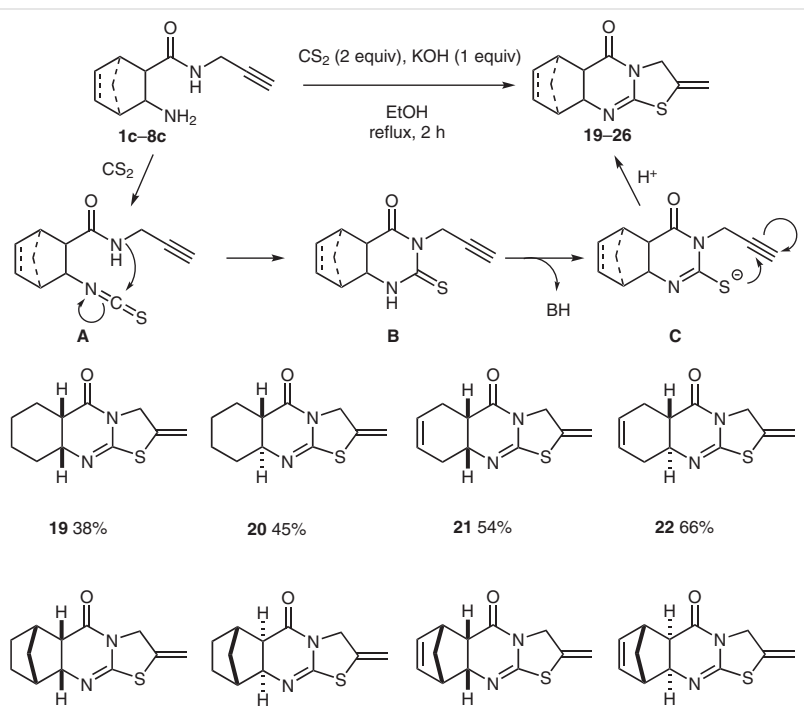

$2372 \%$

$2470 \%$

$2585 \%$

$2681 \%$

Scheme 3 Proposed mechanism of the cascade bicyclisation process and the substrate scope of diverse propargyl-substituted alicyclic $\beta$ amino amides

flexibility of the starting alicyclic amino propargylamide. The yield changed from a mere $38 \%$ for cyclohexane derivative 19 to $72-81 \%$ for tetracyclic derivatives $23,24,25$ and 26. Moreover, the presence of one equivalent of potassium hydroxide led to partial epimerisation in the cases of ciscyclohexane 19 and cis-cyclohexene 21, leading to transcyclohexane $\mathbf{2 0}$ and trans-cyclohexene 22, respectively. This accounts for the lower yields observed for these final products (Scheme 3). 
Alternative syntheses of fused thiazolo derivatives from alicyclic isothiocyanates bearing an ester group and bifunctional reagents, such as propargylamine, are feasible..$^{20,23}$

Alicyclic ethyl 2-isothiocyanatocarboxylates 9b-18b were treated with one equivalent each of propargylamine and potassium carbonate at reflux temperature in ethanol. Products 19, 21 and 25-32 were isolated with relatively high yields ranging from $68 \%$ to $85 \%$. This procedure showed no decrease in the yield when using more flexible alicyclic starting materials. Moreover, with the use of a slightly weaker base such as potassium carbonate, partial epimerisation of cis-cyclohexane $\mathbf{1 9}$ and cis-cyclohexene $\mathbf{2 1}$ derivatives could be avoided (Scheme 4 ).

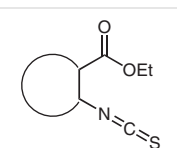

9b-18b<smiles>C=C1CN2C(=O)C3CCCCC3N=C2S1</smiles>

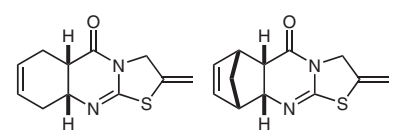

$2172 \%$<smiles>C=C1CN/C(=N\C2CCC(C(=O)OCC)C2C(=O)O)S1</smiles><smiles>C=C1CN2C(=O)C3CCCCCC3N=C2S1</smiles>

$2972 \%$

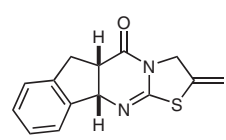

$3281 \%$

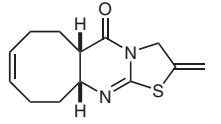

$3180 \%$

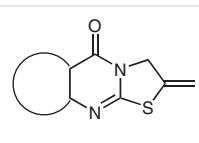

$19,21,25-32$

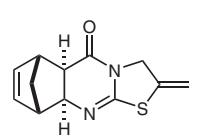

$2681 \%$

Scheme 4 Substrate scope of the diverse alicyclic ethyl 2-isothiocyanatocarboxylates

Product formation involved a two-step cascade reaction starting with the formation of thiourea intermediate $\mathbf{A}^{\prime}$, followed by a favoured base-catalysed intramolecular 5-exodig ring closure leading to methylenethiazolidin-2-ylidene intermediate $\mathbf{D}^{\prime}$. Finally, a base-catalysed amidation delivered the target ring system (Scheme 5).

According to the proposed mechanistic pathway, intramolecular 5-exo-dig ring closure took place first. This is supported by the fact that in the reaction of trans-ethyl-2isothiocyanatocyclopentane-1-carboxylate (14b), carried out under the same conditions, only methylenethiazolidin2-ylidene intermediate $\mathbf{2 8}$ was isolated and characterised by NMR spectroscopy. Similar reactivity was observed in earlier studies related to the cyclisation of the cis- and trans-1,3-difunctional 1,2-disubstituted cyclopentane derivatives, such as cis- and trans-2-amino-1-cyclopentanecarboxylic acids and their isothiocyanate esters. Note that

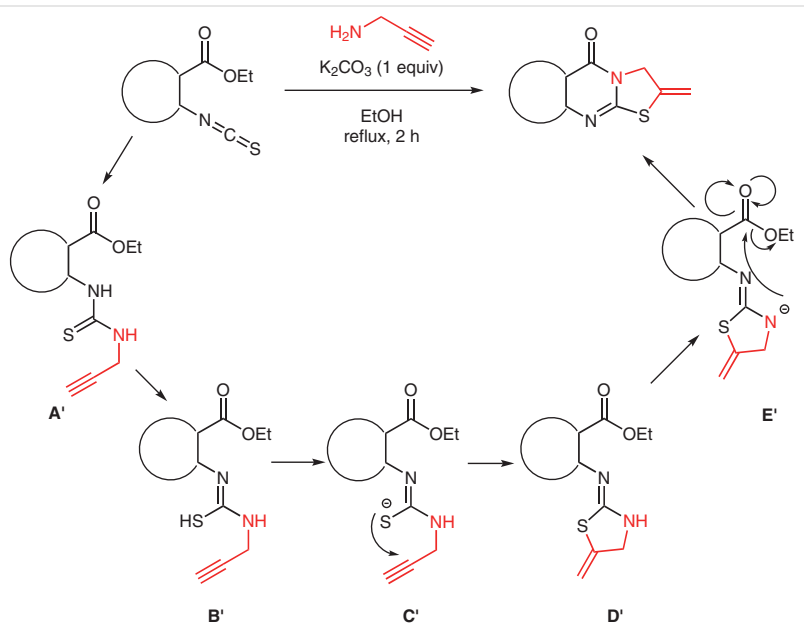

Scheme 5 Proposed mechanism of the cascade process

cis isomers react readily, whereas their trans counterparts do not undergo ring closure in most cases. ${ }^{25,26}$

The possibility of the RDA reaction of both di-endo 25 and di-exo 26 norbornene derivatives was explored under microwave irradiation. The di-endo $\mathbf{2 5}$ or di-exo $\mathbf{2 6}$ norbornene derivative was dissolved in a mixture of toluene/methanol $(4: 1,1 \mathrm{~mL})$ and heated under microwave irradiation at $140{ }^{\circ} \mathrm{C}$ for 30 minutes leading to the formation of 2-methylene- $2 \mathrm{H}$-thiazolo[3,2-a]pyrimidin-5(3H)-one (33) (Scheme 6). The final product was obtained after evaporation of the solvent and crystallisation from ether, and was subsequently characterised by NMR spectroscopy. Surprisingly, the yield of the RDA decomposition was extremely high: $96 \%$ and $98 \%$ starting from the di-endo and di-exo isomer, respectively. This result can be easily explained by the high electron delocalisation throughout the ring system of product 33.

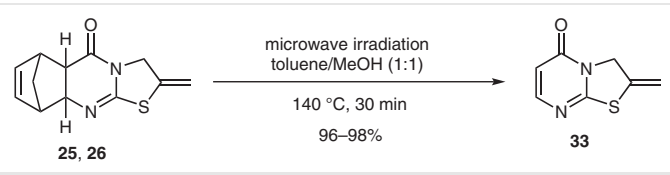

Scheme 6 RDA reactions of norbornene-condensed derivatives

The extremely high yield of the RDA decomposition was intriguing and prompted us to explore the possibility of converting the free bases of $\mathrm{N}$-Boc-protected propargylamides $\mathbf{7 c}$ and $\mathbf{8 c}$ and norbornene ethyl 2-isothiocyanatocarboxylates 11b and 12b into 2-methylene- $2 \mathrm{H}$-thiazolo[3,2-a]pyrimidin-5(3H)-one (33) via a one-pot dominoRDA process under microwave irradiation. Because both domino processes work under the same optimum conditions, the optimisation of the conditions of the new one-pot domino-RDA process was investigated only with $\mathrm{N}$-Boc- 
protected propargylamides $\mathbf{7 c}$ and $\mathbf{8 c}$. Afterwards, the optimum conditions were applied to norbornene ethyl 2-isothiocyanatocarboxylates $\mathbf{1 1 b}$ and $\mathbf{1 2 b}$.

After deprotection of di-exo N-Boc-protected propargylamides $\mathbf{7 b}$ or $\mathbf{8 b}$, the free base was used without further purification. On using ethanol alone as the solvent for the reaction, the required temperature barrier could not be reached and only the product of the domino reaction was detected. Subsequently, the use of ethanol/water (2:1) was investigated, which led to decomposition and none of the domino or RDA product. The same result was obtained when using a mixture of toluene/methanol (4:1) for 60 minutes and 30 minutes, respectively, at $140{ }^{\circ} \mathrm{C}$ (Table 1 ).

Table 1 One-Pot Synthesis of 2-Methylene-2H-thiazolo[3,2-a]pyrimidin-5(3H)-one (33)

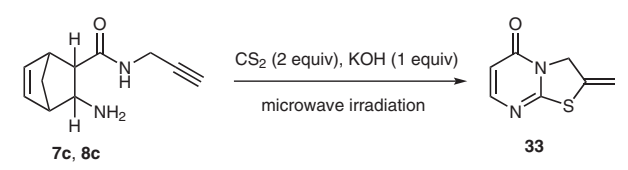

\begin{tabular}{lll}
\hline Solvent & Conditions & Yield \\
\hline EtOH & $60 \mathrm{~min}, 120^{\circ} \mathrm{C}$ & domino product only \\
$\mathrm{EtOH} / \mathrm{H}_{2} \mathrm{O}(2: 1)$ & $60 \mathrm{~min}, 140{ }^{\circ} \mathrm{C}$ & decomposition \\
toluene/MeOH $(4: 1)$ & $60 \mathrm{~min}, 140{ }^{\circ} \mathrm{C}$ & decomposition \\
toluene/MeOH $(4: 1)$ & $30 \mathrm{~min}, 140{ }^{\circ} \mathrm{C}$ & decomposition \\
toluene/MeOH $(4: 1)$ & $30 \mathrm{~min}, 90^{\circ} \mathrm{C}$ followed by & $60 \%$ \\
& $30 \mathrm{~min}, 140{ }^{\circ} \mathrm{C}$ & \\
toluene/MeOH $(4: 1)$ & $15 \mathrm{~min}, 90^{\circ} \mathrm{C}$ followed by & $68 \%$ \\
& $30 \mathrm{~min}, 140{ }^{\circ} \mathrm{C}$ & \\
\hline
\end{tabular}

Therefore, the use of two different temperature barriers was investigated. Indeed, the one-pot domino-RDA reaction worked successfully using a temperature of $90{ }^{\circ} \mathrm{C}$ for 30 minutes followed by $140{ }^{\circ} \mathrm{C}$ for 30 minutes. However, the optimum result was obtained by using a temperature of 90 ${ }^{\circ} \mathrm{C}$ for 15 minutes and then $140{ }^{\circ} \mathrm{C}$ for 30 minutes, with toluene/methanol ( $4: 1)$ as the solvent.

The one-pot procedure was also performed with norbornene ethyl 2-isothiocyanatocarboxylates 11b and 12b under the optimum conditions. Despite similar yields being obtained, the final product needed to be purified by column chromatography.

Concerning the antiproliferative properties of the presented quinazolinone analogues, modest activity was detected. The MCF-7 breast cancer cell line was shown to be the most sensitive to nearly all the tested compounds, with a maximum of above $60 \%$ growth inhibition exhibited by compound 32 at a concentration of $30 \mu \mathrm{M}$. In fact, compound 32 demonstrated antiproliferative effects of more than $10 \%$ against all the tested cell lines, with a slight selectivity towards the cancer cell lines. MCF-7, which is an oestrogen receptor positive and HER2-negative breast cancer cell line, and the MDA-MB-231 (triple negative) breast can- cer cell line were the most sensitive towards the tested quinazolinone analogues. The indane moiety in the molecular structure seems to contribute to the in vitro anticancer effects (see the Supporting information).

In conclusion, although the reactions of cyclic and alicyclic $\beta$-amino propargylamides with carbon disulfide took place in a regioselective manner and led only to the favoured 5-exo-dig products, the obtained yields were relatively low for the flexible cyclic amides, notably, for compounds 19 and 20 . This is caused by the strong base needed for the reaction. On the other hand, the reaction of ethyl 2isothiocyanatocarboxylates with propargylamine gave higher yields, while preserving the regioselectivity of the cascade process when using a weaker base. The RDA reaction of norbornene derivatives proceeded remarkably well, leading to very high yields of product $\mathbf{3 3}$ (up to $98 \%$ ).

Boc-protected amino acids 1a-8a were prepared according to a literature procedure. ${ }^{21,22}$ The propargyl-substituted alicyclic compounds $\mathbf{1 b}-\mathbf{8 b}$ were prepared according to the procedure described in our previous work. ${ }^{21,22}$ Column chromatography was performed using Merck silica gel (60 / 70-230 mesh ASTM). Melting points were determined with a Hinotex-X4 micro melting point apparatus (Hinotek, Ningbo, China) and are uncorrected. ${ }^{1} \mathrm{H}$ NMR $(500.20 \mathrm{MHz})$ and ${ }^{13} \mathrm{C}$ NMR (125.62 MHz) spectra were recorded in $\mathrm{CDCl}_{3}$ at ambient temperature with a Bruker AV NEO Ascend 500 spectrometer (Bruker Biospin, Karlsruhe, Germany) by employing a Double Resonance Broad Band Probe (BBO). Chemical shifts are given in $\delta$ (ppm) relative to tetramethylsilane (TMS) as an internal standard. The HRMS flow-injection analysis was performed with a Thermo Scientific Q Exactive Plus hybrid quadrupole-Orbitrap (Thermo Fisher Scientific, Waltham, MA, USA) mass spectrometer coupled to a Waters Acquity I-Class UPLC ${ }^{\mathrm{TM}}$ (Waters, Manchester, UK). Microwave-promoted reactions were carried out in sealed reaction vials $(10 \mathrm{~mL})$ in a microwave reactor (CEM, Discover, SP) (CEM Corporation, Matthews, NC, USA).

\section{Ethyl 2-Isothiocyanatocarboxylates 9b-18b; General Procedure}

To a stirred mixture of $\mathrm{CHCl}_{3}(15 \mathrm{~mL})$, water $(8 \mathrm{~mL})$, thiophosgene $(0.57 \mathrm{~g}, 5 \mathrm{mmol})$ and $\mathrm{NaHCO}_{3}(1.26 \mathrm{~g}, 15 \mathrm{mmol})$ was added dropwise a solution of alicyclic ethyl ester hydrochloride $\mathbf{9 a - 1 8 a}(5 \mathrm{mmol})$ in water $(8 \mathrm{~mL})$. After stirring for $3 \mathrm{~h}$ at $40{ }^{\circ} \mathrm{C}$, the $\mathrm{CHCl}_{3}$ layer was separated and the aqueous solution was extracted with $\mathrm{CHCl}_{3}(3 \times 30 \mathrm{~mL})$. The combined organic layer was dried over $\mathrm{Na}_{2} \mathrm{SO}_{4}$ and filtered. After evaporation, the residue was purified by column chromatography (silica gel, $n$-hexane/EtOAc, 7:3). The ${ }^{1} \mathrm{H}$ NMR spectra indicated that the obtained oily compounds $\mathbf{9 b}-\mathbf{1 8 b}$ had a purity of $>98 \%$. The analytical data of products $\mathbf{9 b - 1 4 b}$ are identical to those reported in the literature..$^{24,25}$

\section{(1 $\left.S^{*}, 2 R^{*}\right)$-Ethyl 2-Isothiocyanatocycloheptanecarboxylate (15b)}

Yield: $0.81 \mathrm{~g}(72 \%)$; light yellow oil.

${ }^{1} \mathrm{H}$ NMR $\left(500.20 \mathrm{MHz}, \mathrm{CDCl}_{3}, 30{ }^{\circ} \mathrm{C}\right): \delta=4.45-4.56(\mathrm{~m}, 1 \mathrm{H}, \mathrm{HC} 1)$, 4.11-4.27 (m, $2 \mathrm{H}, \mathrm{H}_{2} \mathrm{C}$ ), 2.55-2.66 ( $\mathrm{m}, 1 \mathrm{H}, \mathrm{HC}$ ), 2.01-2.15 (m, $2 \mathrm{H}$, $\left.\mathrm{H}_{2} \mathrm{C} 2\right), 1.45-1.91(\mathrm{~m}, 8 \mathrm{H}), 1.29\left(\mathrm{t}, J=7.0 \mathrm{~Hz}, 3 \mathrm{H}, \mathrm{H}_{3} \mathrm{C}\right)$.

${ }^{13} \mathrm{C} \mathrm{NMR}\left(125.62 \mathrm{MHz}, \mathrm{CDCl}_{3}, 30{ }^{\circ} \mathrm{C}\right): \delta=172.7$ (CO), 132.0 (NCS), 61.1 $\left(\mathrm{CH}_{2} \mathrm{CH}_{3}\right.$ ), 58.2 (C2), 49.5 (C1), 34.0 (C3), 26.7 (C5), 25.5 (C7), 24.8 (C6), 22.9 (C4), $14.2\left(\mathrm{CH}_{2} \mathrm{CH}_{3}\right)$. 
HRMS (ESI): $m / z[M+\mathrm{H}]^{+}$calcd for $\mathrm{C}_{11} \mathrm{H}_{18} \mathrm{NO}_{2} \mathrm{~S}$ : 228.10528; found: 228.10529 .

$\left(1 S^{*}, 2 R^{*}\right)$-Ethyl 2-Isothiocyanatocyclooctanecarboxylate (16b)

Yield: $0.83 \mathrm{~g}$ (69\%); light yellow oil.

${ }^{1} \mathrm{H}$ NMR $\left(500.20 \mathrm{MHz}, \mathrm{CDCl}_{3}, 30{ }^{\circ} \mathrm{C}\right): \delta=4.31-4.44(\mathrm{~m}, 1 \mathrm{H}, \mathrm{HC} 1)$, 4.11-4.29 (m, $\left.2 \mathrm{H}, \mathrm{H}_{2} \mathrm{C}\right), 2.69-2.80$ ( $\left.\mathrm{m}, 1 \mathrm{H}, \mathrm{HC}\right), 1.92-2.19(\mathrm{~m}, 3 \mathrm{H})$, 1.67-1.88 (m, $3 \mathrm{H}), 1.44-1.66(\mathrm{~m}, 6 \mathrm{H}), 1.30\left(\mathrm{t}, J=7.2 \mathrm{~Hz}, 3 \mathrm{H}, \mathrm{H}_{3} \mathrm{C}\right)$.

${ }^{13} \mathrm{C}$ NMR (125.62 MHz, $\left.\mathrm{CDCl}_{3}, 30{ }^{\circ} \mathrm{C}\right): \delta=173.1(\mathrm{CO}), 132.2(\mathrm{NCS}), 61.2$ $\left(\mathrm{CH}_{2} \mathrm{CH}_{3}\right), 58.5$ (C2), 46.3 (C1), 31.8 (C3), 27.1 (C8), 26.3 (C5), 24.8 (C6), 23.6 (C7), 22.4 (C4), $14.2\left(\mathrm{CH}_{2} \mathrm{CH}_{3}\right)$.

HRMS (ESI): $m / z[M+H]^{+}$calcd for $\mathrm{C}_{12} \mathrm{H}_{20} \mathrm{NO}_{2} \mathrm{~S}: 242.12126$; found: 242.12012.

$\left(1 S^{*}, 8 R^{*}\right)$-Ethyl 8-Isothiocyanatocyclooct-4-enecarboxylate (17b) Yield: $0.87 \mathrm{~g}(73 \%)$; light yellow oil.

${ }^{1} \mathrm{H}$ NMR $\left(500.20 \mathrm{MHz}, \mathrm{CDCl}_{3}, 30^{\circ} \mathrm{C}\right): \delta=5.76-5.87(\mathrm{~m}, 1 \mathrm{H}, \mathrm{HC}), 5.59-$ $5.72(\mathrm{~m}, 1 \mathrm{H}, \mathrm{HC}), 4.60(\mathrm{t}, J=5.2 \mathrm{~Hz}, 1 \mathrm{H}, \mathrm{HC}), 4.16(\mathrm{q}, J=7.1 \mathrm{~Hz}, 2 \mathrm{H}$, $\left.\mathrm{H}_{2} \mathrm{C}\right), 2.82(\mathrm{q}, J=4.4 \mathrm{~Hz}, 1 \mathrm{H}, \mathrm{HC} 1), 2.43-2.64(\mathrm{~m}, 2 \mathrm{H}), 1.89-2.24(\mathrm{~m}, 5$ $\mathrm{H}), 1.60-1.74(\mathrm{~m}, 1 \mathrm{H}), 1.27\left(\mathrm{t}, J=7.2 \mathrm{~Hz}, 3 \mathrm{H}, \mathrm{H}_{3} \mathrm{C}\right)$.

${ }^{13} \mathrm{C}$ NMR (125.62 MHz, $\left.\mathrm{CDCl}_{3}, 30{ }^{\circ} \mathrm{C}\right): \delta=174.3$ (CO), 132.1 (NCS), 130.6 (C6), 129.2 (C5), $61.1\left(\mathrm{CH}_{2} \mathrm{CH}_{3}\right), 57.6$ (C3), 45.2 (C2), 34.3 (C1), 28.2 (C7), 23.4 (C4), 22.1 (C8), $14.1\left(\mathrm{CH}_{2} \mathrm{CH}_{3}\right)$.

HRMS (ESI): $m / z$ [M $+\mathrm{H}]^{+}$calcd for $\mathrm{C}_{12} \mathrm{H}_{18} \mathrm{NO}_{2} \mathrm{~S}: 240.10528$; found: 240.10535 .

\section{$\left(1 S^{*}, 2 S^{*}\right)$-Ethyl 1-Isothiocyanato-2,3-dihydro-1H-indene-2-car-} boxylate (18b)

Yield: $0.85 \mathrm{~g}$ (69\%); light yellow solid; $\mathrm{mp} 42-45^{\circ} \mathrm{C}$.

${ }^{1} \mathrm{H}$ NMR $\left(500.20 \mathrm{MHz}, \mathrm{CDCl}_{3}, 30^{\circ} \mathrm{C}\right): \delta=7.23-7.42(\mathrm{~m}, 4 \mathrm{H}, \mathrm{Ar}), 5.39$ (d, $J=6.8 \mathrm{~Hz}, 1 \mathrm{H}, \mathrm{HC}$ ), 4.21-4.37 (m, $\left.2 \mathrm{H}, \mathrm{H}_{2} \mathrm{C}\right), 3.43-3.57(\mathrm{~m}, 2 \mathrm{H}$, $\left.\mathrm{H}_{2} \mathrm{C} 2\right), 3.08$ (q, $\left.J=7.2 \mathrm{~Hz}, 1 \mathrm{H}, \mathrm{HC} 1\right), 1.35\left(\mathrm{t}, J=7.1 \mathrm{~Hz}, 3 \mathrm{H}, \mathrm{H}_{3} \mathrm{C}\right.$ ).

${ }^{13} \mathrm{C}$ NMR (125.62 MHz, $\left.\mathrm{CDCl}_{3}, 30{ }^{\circ} \mathrm{C}\right): \delta=170.1$ (CO), 141.6 (C3a), 138.4 (C7a), 135.5 (NCS), 129.7 (C4), 127.5 (C5), 125.2 (C6), 124.5 (C7), 62.1 (C1), $61.4\left(\mathrm{CH}_{2} \mathrm{CH}_{3}\right), 49.7$ (C2), 32.4 (C3), $14.2\left(\mathrm{CH}_{2} \mathrm{CH}_{3}\right)$. HRMS (ESI): $m / z[\mathrm{M}+\mathrm{H}+\mathrm{MeOH}]^{+}$calcd for $\mathrm{C}_{14} \mathrm{H}_{18} \mathrm{NO}_{3} \mathrm{~S}: 280.09291$; found: 280.10048 .

\section{Alicyclic 2-Methylene-Substituted Thiazolo[2,3-b]quinazolinones from Alicyclic $N$-Boc-Protected Propargylamides; General Proce- dure}

The appropriate Boc-protected propargylamide $\mathbf{1 b}-\mathbf{8 b}(0.60 \mathrm{mmol})$ was deprotected using a $10 \%$ aqueous $\mathrm{HCl}$ solution $(10 \mathrm{~mL})$ at r.t. for 6 h. The aqueous layer was neutralised with $10 \%$ aqueous $\mathrm{NaHCO}_{3}$ solution and extracted with $\mathrm{CH}_{2} \mathrm{Cl}_{2}(3 \times 30 \mathrm{~mL})$. The combined organic phase was dried over $\mathrm{Na}_{2} \mathrm{SO}_{4}$ and the solvent evaporated. The resulting amides were used in the next step without purification. The appropriate free base $(0.60 \mathrm{mmol})$ was dissolved in $\mathrm{EtOH}(10 \mathrm{~mL})$ followed by the addition of $\mathrm{KOH}(0.60 \mathrm{mmol})$ and $\mathrm{CS}_{2}(1.2 \mathrm{mmol})$. The reaction mixture was then stirred at reflux temperature for $2 \mathrm{~h}$ or until completion of the reaction (monitored by TLC). The solvent mixture was evaporated along with residual $\mathrm{CS}_{2}$. The crude product was diluted with water $(5 \mathrm{~mL})$ and was extracted with $\mathrm{CH}_{2} \mathrm{Cl}_{2}(3 \times 10 \mathrm{~mL})$ and the combined organic phase was dried over $\mathrm{Na}_{2} \mathrm{SO}_{4}$. After evaporation, the obtained products $\mathbf{2 0 - 2 6}$ were crystallised using $\mathrm{Et}_{2} \mathrm{O}$. The only exception was compound $\mathbf{1 9}$. In this case, the crude product was purified by column chromatography using EtOAc as the eluent to separate the two epimers formed.
Alicyclic 2-Methylene-Substituted Thiazolo[2,3-b]quinazolinones from Alicyclic Ethyl-2-isothiocyanatocarboxylates; General Procedure

A mixture of the appropriate alicyclic ethyl-2-isothiocyanatocarboxylate $\mathbf{9 b}-\mathbf{1 8 b}(0.50 \mathrm{mmol})$ and $\mathrm{K}_{2} \mathrm{CO}_{3}(0.50 \mathrm{mmol})$ was dissolved in EtOH $(10 \mathrm{~mL})$, followed by the addition of propargylamine $(0.7$ $\mathrm{mmol}$ ). The resulting solution was stirred for $2 \mathrm{~h}$ at reflux temperature. After completion of reaction as indicated by TLC, the mixture was concentrated and directly purified by column chromatography ( $n$-hexane/EtOAc, 1:2) to give the desired products 19, 21 and 25-32.

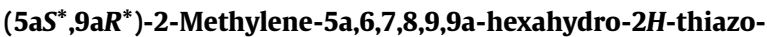 lo[2,3-b]quinazolin-5(3H)-one (19)}

Yield: $0.09 \mathrm{~g}(68 \%)$; light brown solid; $\mathrm{mp} 83-86^{\circ} \mathrm{C}$.

${ }^{1} \mathrm{H} \mathrm{NMR}\left(500.20 \mathrm{MHz}, \mathrm{CDCl}_{3}, 30{ }^{\circ} \mathrm{C}\right): \delta=5.30\left(\mathrm{~s}, 1 \mathrm{H},=\mathrm{CH}_{2}\right), 5.20(\mathrm{~s}, 1$ $\left.\mathrm{H},=\mathrm{CH}_{2}\right), 4.65\left(\mathrm{~s}, 2 \mathrm{H}, \mathrm{H}_{2} \mathrm{C} 3\right), 3.78$ (s, $\left.1 \mathrm{H}, \mathrm{HC} 5 \mathrm{a}\right), 2.59$ (s, $\left.1 \mathrm{H}, \mathrm{HC} 9 \mathrm{a}\right)$, $1.34-1.76(\mathrm{~m}, 8 \mathrm{H})$.

${ }^{13} \mathrm{C}$ NMR (125.62 MHz, $\left.\mathrm{CDCl}_{3}, 30{ }^{\circ} \mathrm{C}\right): \delta=169.7$ (C5), 155.1 (C10a), 134.6 (C2), $106.7\left(=\mathrm{CH}_{2}\right.$ ), 56.7 (C9a), 52.0 (C3), 40.6 (C5a), 29.6 (C9), 23.7 (C6), 23.3 (C7), 22.7 (C8).

HRMS (ESI): $m / z[M+H]^{+}$calcd for $\mathrm{C}_{11} \mathrm{H}_{15} \mathrm{~N}_{2} \mathrm{OS}$ : 223.08996; found: 223.09011 .

$\left(5 \mathrm{a} S^{*}, 9 \mathrm{a} S^{*}\right)$-2-Methylene-5a,6,7,8,9,9a-hexahydro-2H-thiazolo[2,3b]quinazolin-5(3H)-one (20)

Yield: $0.06 \mathrm{~g}$ (45\%); light brown solid; $\mathrm{mp} 124-128^{\circ} \mathrm{C}$.

${ }^{1} \mathrm{H}$ NMR $\left(500.20 \mathrm{MHz}, \mathrm{CDCl}_{3}, 30{ }^{\circ} \mathrm{C}\right): \delta=5.31\left(\mathrm{~s}, 1 \mathrm{H},=\mathrm{CH}_{2}\right), 5.21(\mathrm{~s}, 1$ $\left.\mathrm{H},=\mathrm{CH}_{2}\right), 4.78\left(\mathrm{~d}, J=15.7 \mathrm{~Hz}, 1 \mathrm{H}, \mathrm{H}_{2} \mathrm{C} 3\right), 4.53(\mathrm{~d}, J=15.7 \mathrm{~Hz}, 1 \mathrm{H}$, $\mathrm{H}_{2} \mathrm{C} 3$ ), 3.16-3.27 (m, $1 \mathrm{H}, \mathrm{HC} 5 \mathrm{a}$ ), 2.32-2.43 (m, $1 \mathrm{H}, \mathrm{HC} 9 \mathrm{a}$ ), 2.22-2.31 $\left(\mathrm{m}, 1 \mathrm{H}, \mathrm{H}_{2} \mathrm{C}\right), 1.94-2.04\left(\mathrm{~m}, 1 \mathrm{H}, \mathrm{H}_{2} \mathrm{C}\right), 1.84\left(\mathrm{~d}, J=10.1 \mathrm{~Hz}, 2 \mathrm{H}, \mathrm{H}_{3} \mathrm{C}\right)$, $1.64\left(\mathrm{~s}, 1 \mathrm{H}, \mathrm{H}_{2} \mathrm{C}\right), 1.37-1.48\left(\mathrm{~m}, 1 \mathrm{H}, \mathrm{H}_{2} \mathrm{C}\right), 1.20-1.26\left(\mathrm{~m}, 2 \mathrm{H}, \mathrm{H}_{2} \mathrm{C}\right)$.

${ }^{13} \mathrm{C}$ NMR (125.62 MHz, $\left.\mathrm{CDCl}_{3}, 30{ }^{\circ} \mathrm{C}\right): \delta=169.7$ (C5), 155.8 (C10a), 134.6 (C2), 106.9 (= $\mathrm{CH}_{2}$ ), 60.1 (C9a), 52.1 (C3), 43.0 (C5a), 34.3 (C9), 25.0 (C6), 24.9 (C7), 24.9 (C8).

HRMS (ESI): $m / z[\mathrm{M}+\mathrm{H}]^{+}$calcd for $\mathrm{C}_{11} \mathrm{H}_{15} \mathrm{~N}_{2} \mathrm{OS}$ : 223.08996; found: 223.09009 .

\section{$\left(5 \mathrm{a} S^{*}, 9 \mathrm{a}{ }^{*}\right)$-2-Methylene-5a,6,9,9a-tetrahydro-2H-thiazolo-} [2,3-b]quinazolin-5(3H)-one (21)

Yield: $0.095 \mathrm{~g}$ (72\%); light brown solid; $\mathrm{mp} 125-128^{\circ} \mathrm{C}$.

${ }^{1} \mathrm{H}$ NMR $\left(500.20 \mathrm{MHz}, \mathrm{CDCl}_{3}, 30{ }^{\circ} \mathrm{C}\right): \delta=5.63\left(\mathrm{~s}, 2 \mathrm{H},=\mathrm{CH}_{2}\right), 5.25(\mathrm{~s}, 1$ H, HC8), 5.15 (s, $1 \mathrm{H}, \mathrm{HC7}$ ), 4.71 (d, $J=13.5 \mathrm{~Hz}, 1 \mathrm{H}, \mathrm{H}_{2} \mathrm{C} 3$ ), 4.49 (d, $J=$ $13.5 \mathrm{~Hz}, 1 \mathrm{H}, \mathrm{H}_{2} \mathrm{C} 3$ ), 3.46-3.63 (m, $\left.1 \mathrm{H}, \mathrm{HC} 8 \mathrm{a}\right), 2.50-2.75(\mathrm{~m}, 2 \mathrm{H}$, $\mathrm{H}_{2} \mathrm{C} 9$ ), 2.26-2.41 (m, $\left.1 \mathrm{H}, \mathrm{HC} 4 \mathrm{a}\right), 2.07-2.26$ ( $\mathrm{m}, 2 \mathrm{H}, \mathrm{H}_{2} \mathrm{C6}$ ).

${ }^{13} \mathrm{C}$ NMR (125.62 MHz, $\left.\mathrm{CDCl}_{3}, 30{ }^{\circ} \mathrm{C}\right): \delta=169.2$ (C5), 155.6 (C10a), 134.4 (C2), 125.5 (C7), $125.1(\mathrm{C} 8), 106.9\left(=\mathrm{CH}_{2}\right), 56.8$ (C9a), 52.2 (C3), 39.3 (C5a), 33.9 (C9), 25.9 (C6).

HRMS (ESI): $m / z[M+H]^{+}$calcd for $\mathrm{C}_{11} \mathrm{H}_{13} \mathrm{~N}_{2} \mathrm{OS}$ : 221.07432; found: 221.07431.

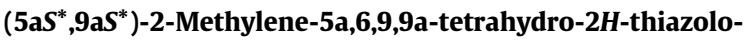
[2,3-b]quinazolin-5(3H)-one (22)

Yield: $0.084 \mathrm{~g}(66 \%)$; light brown solid; $\mathrm{mp} 128-130^{\circ} \mathrm{C}$.

${ }^{1} \mathrm{H}$ NMR $\left(500.20 \mathrm{MHz}, \mathrm{CDCl}_{3}, 30^{\circ} \mathrm{C}\right): \delta=5.69\left(\mathrm{~s}, 2 \mathrm{H},=\mathrm{CH}_{2}\right), 5.32(\mathrm{q}, J=$ $2.2 \mathrm{~Hz}, 1 \mathrm{H}, \mathrm{HC}$ ), 5.21 (q, J = 2.2 Hz, $1 \mathrm{H}, \mathrm{HC}$ ), 4.78 (d, J = $15.5 \mathrm{~Hz}, 1 \mathrm{H}$, $\mathrm{H}_{2} \mathrm{C} 3$ ), 4.56 (d, $J=15.5 \mathrm{~Hz}, 1 \mathrm{H}, \mathrm{H}_{2} \mathrm{C} 3$ ), 3.51-3.65 (m, $1 \mathrm{H}, \mathrm{HC} 5 \mathrm{a}$ ), 2.592.74 ( $\left.\mathrm{m}, 2 \mathrm{H}, \mathrm{H}_{2} \mathrm{C} 9\right), 2.31-2.41$ (m, $\left.1 \mathrm{H}, \mathrm{HC} 9 \mathrm{a}\right), 2.15-2.29$ (m, $2 \mathrm{H}$, $\mathrm{H}_{2} \mathrm{C} 6$ ). 
${ }^{13} \mathrm{C}$ NMR (125.62 MHz, $\left.\mathrm{CDCl}_{3}, 30{ }^{\circ} \mathrm{C}\right): \delta=169.2(\mathrm{C} 5), 155.6$ (C10a), 134.4 (C2), 125.5 (C7), 125.1 (C8), $106.9\left(=\mathrm{CH}_{2}\right), 106.2$ (C9a), 52.2 (C3), 39.3 (C5a), 33.9 (C9), 25.9 (C6).

HRMS (ESI): $m / z[M+H]^{+}$calcd for $\mathrm{C}_{11} \mathrm{H}_{13} \mathrm{~N}_{2} \mathrm{OS}$ : 221.07431; found: 221.07455 .

$\left(5 \mathrm{a} S^{*}, 6 S^{*}, 9 R^{*}, 9 \mathrm{a} R^{*}\right)-2-M e t h y l e n e-5 a, 6,7,8,9,9 a-h e x a h y d r o-2 H-6,9-$ methanothiazolo[2,3-b]quinazolin-5(3H)-one (23)

Yield: $0.10 \mathrm{~g}$ (72\%); light brown solid; $\mathrm{mp} 113-116{ }^{\circ} \mathrm{C}$.

${ }^{1} \mathrm{H}$ NMR $\left(500.20 \mathrm{MHz}, \mathrm{CDCl}_{3}, 30{ }^{\circ} \mathrm{C}\right): \delta=5.28\left(\mathrm{~s}, 1 \mathrm{H},=\mathrm{CH}_{2}\right), 5.18(\mathrm{~s}, 1$ $\left.\mathrm{H},=\mathrm{CH}_{2}\right), 4.57-4.62\left(\mathrm{~m}, 2 \mathrm{H}, \mathrm{H}_{2} \mathrm{C} 3\right), 3.83(\mathrm{~d}, J=8.5 \mathrm{~Hz}, 1 \mathrm{H}, \mathrm{HC} 5 \mathrm{a}), 2.69$ (s, $\left.1 \mathrm{H}, \mathrm{H}_{2} \mathrm{C} 9\right), 2.47\left(\mathrm{~s}, 1 \mathrm{H}, \mathrm{H}_{2} \mathrm{C}\right), 2.46\left(\mathrm{~s}, 1 \mathrm{H}, \mathrm{H}_{2} \mathrm{C}\right), 1.18-1.67(\mathrm{~m}, 6 \mathrm{H})$.

${ }^{13} \mathrm{C}$ NMR (125.62 MHz, $\left.\mathrm{CDCl}_{3}, 30{ }^{\circ} \mathrm{C}\right): \delta=152.5$ (C5), 133.0 (C10a), $106.3(\mathrm{C} 2), 66.3\left(=\mathrm{CH}_{2}\right), 52.5$ (C9a), 47.2 (C3), 45.8 (C5a), 43.1 (C9, C6), $34.5\left(\mathrm{CH}_{2}\right), 29.7$ (C8), $26.1(\mathrm{C} 7)$.

HRMS (ESI): $m / z[M+H]^{+}$calcd for $\mathrm{C}_{12} \mathrm{H}_{15} \mathrm{~N}_{2} \mathrm{OS}$ : 235.08996; found: 235.09015.

$\left(5 a R^{*}, 6 S^{*}, 9 R^{*}, 9 a S^{*}\right)-2-M e t h y l e n e-5 a, 6,7,8,9,9 a-h e x a h y d r o-2 H-6,9-$ methanothiazolo[2,3-b]quinazolin-5(3H)-one (24)

Yield: $0.098 \mathrm{~g}$ (70\%); light brown solid; $\mathrm{mp} 118-121^{\circ} \mathrm{C}$.

${ }^{1} \mathrm{H}$ NMR $\left(500.20 \mathrm{MHz}, \mathrm{CDCl}_{3}, 30{ }^{\circ} \mathrm{C}\right): \delta=5.31\left(\mathrm{~s}, 1 \mathrm{H},=\mathrm{CH}_{2}\right), 5.21(\mathrm{~s}, 1$ $\left.\mathrm{H},=\mathrm{CH}_{2}\right), 4.64-4.74\left(\mathrm{~m}, 2 \mathrm{H}, \mathrm{H}_{2} \mathrm{C} 3\right), 4.16(\mathrm{q}, J=3.8 \mathrm{~Hz}, 1 \mathrm{H}, \mathrm{HC} 5 \mathrm{a}), 2.78$ (s, $1 \mathrm{H}, \mathrm{H}_{2} \mathrm{C} 9$ ), 2.64-2.72 (m, $2 \mathrm{H}, \mathrm{H}_{2} \mathrm{C}$ ), 1.35-1.56 (m, $\left.5 \mathrm{H}\right), 1.18-1.29$ ( $\mathrm{m}, 1 \mathrm{H})$.

${ }^{13} \mathrm{C}$ NMR (125.62 MHz, $\left.\mathrm{CDCl}_{3}, 30{ }^{\circ} \mathrm{C}\right): \delta=152.5$ (C5), 133.2 (C10a), 106.3 (C2), $66.3\left(=\mathrm{CH}_{2}\right), 52.5$ (C9a), 47.2 (C3), 45.8 (C5a), 43.1 (C9, C6), $34.5\left(\mathrm{CH}_{2}\right), 29.7$ (C8), 26.1 (C7).

HRMS (ESI): $m / z[M+H]^{+}$calcd for $\mathrm{C}_{12} \mathrm{H}_{15} \mathrm{~N}_{2} \mathrm{OS}$ : 235.08996; found: 235.09020 .

$\left(5 \mathrm{a} S^{*}, 6 R^{*}, 9 S^{*}, 9 \mathrm{a} R^{*}\right)-2-M e t h y l e n e-5 a, 6,9,9 a-t e t r a h y d r o-2 H-6,9-$ methanothiazolo[2,3-b]quinazolin-5(3H)-one (25)

Yield: $0.12 \mathrm{~g}(85 \%)$; light brown solid; $\mathrm{mp} 136-139{ }^{\circ} \mathrm{C}$.

${ }^{1} \mathrm{H}$ NMR $\left(500.20 \mathrm{MHz}, \mathrm{CDCl}_{3}, 30^{\circ} \mathrm{C}\right): \delta=6.17(\mathrm{~d}, J=10.7 \mathrm{~Hz}, 2 \mathrm{H}, \mathrm{HC}$, $\mathrm{HC7}), 5.26\left(\mathrm{~s}, 1 \mathrm{H},=\mathrm{CH}_{2}\right), 5.16\left(\mathrm{~s}, 1 \mathrm{H},=\mathrm{CH}_{2}\right), 4.49-4.62\left(\mathrm{~m}, 2 \mathrm{H}, \mathrm{H}_{2} \mathrm{C} 3\right)$, $4.40(\mathrm{q}, J=4.0 \mathrm{~Hz}, 1 \mathrm{H}, \mathrm{HC} 5 \mathrm{a}), 3.48$ (s, $1 \mathrm{H}, \mathrm{HC}$ ), 3.39 (s, $1 \mathrm{H}, \mathrm{HC}$ ), 2.91 (q, $J=4.0 \mathrm{~Hz}, 1 \mathrm{H}, \mathrm{HC} 9 \mathrm{a}), 1.47$ (d, $J=8.9 \mathrm{~Hz}, 1 \mathrm{H}, \mathrm{H}_{2} \mathrm{C}$ ), 1.36 (d, $J=$ $\left.8.9 \mathrm{~Hz}, 1 \mathrm{H}, \mathrm{H}_{2} \mathrm{C}\right)$.

${ }^{13} \mathrm{C}$ NMR (125.62 MHz, $\left.\mathrm{CDCl}_{3}, 30{ }^{\circ} \mathrm{C}\right): \delta=167.5$ (C5), 152.5 (C10a), 136.5 (C8), 135.2 (C7), 133.3 (C2), $106.3\left(=\mathrm{CH}_{2}\right), 63.3$ (C9a), 52.1 (C3), 49.9 (C5a), 48.8 (C9), 46.2 (C6), $42.4\left(\mathrm{CH}_{2}\right)$.

HRMS (ESI): $m / z$ [M $+\mathrm{H}]^{+}$calcd for $\mathrm{C}_{12} \mathrm{H}_{13} \mathrm{~N}_{2} \mathrm{OS}$ : 233.07420; found: 233.07431 .

$\left(5 \mathrm{a} R^{*}, 6 R^{*}, 9 S^{*}, 9 \mathrm{a} S^{*}\right)$-2-Methylene-5a,6,9,9a-tetrahydro-2H-6,9methanothiazolo[2,3-b]quinazolin-5(3H)-one (26)

Yield: $0.11 \mathrm{~g}(81 \%)$; light brown solid; $\mathrm{mp} 118-121^{\circ} \mathrm{C}$.

${ }^{1} \mathrm{H} \mathrm{NMR}\left(500.20 \mathrm{MHz}, \mathrm{CDCl}_{3}, 30^{\circ} \mathrm{C}\right): \delta=6.31(\mathrm{~s}, 1 \mathrm{H}, \mathrm{HC} 8), 6.20(\mathrm{~s}, 1 \mathrm{H}$, HC7), 5.31 (q, J = 2.2 Hz, $\left.1 \mathrm{H},=\mathrm{CH}_{2}\right), 5.21\left(\mathrm{q}, J=2.2 \mathrm{~Hz}, 1 \mathrm{H},=\mathrm{CH}_{2}\right), 4.86$ (s, $2 \mathrm{H}, \mathrm{H}_{2} \mathrm{C} 3$ ), 3.80 (d, J = 8.4 Hz, $1 \mathrm{H}, \mathrm{HC} 5 \mathrm{a}$ ), 3.31 (s, $1 \mathrm{H}, \mathrm{HC}$ ), 3.13 (s, $1 \mathrm{H}, \mathrm{HC}$ ), 2.36 (d, J = 8.4 Hz, $1 \mathrm{H}, \mathrm{HC} 9 \mathrm{a}), 1.48$ (d, J = 9.2 Hz, $1 \mathrm{H}, \mathrm{H}_{2} \mathrm{C}$ ), $1.42\left(\mathrm{~d}, J=9.2 \mathrm{~Hz}, 1 \mathrm{H}, \mathrm{H}_{2} \mathrm{C}\right)$.

${ }^{13} \mathrm{C}$ NMR (125.62 MHz, $\left.\mathrm{CDCl}_{3}, 30{ }^{\circ} \mathrm{C}\right): \delta=167.2$ (C5), 153.1 (C10a), 138.9 (C8), 136.2 (C7), 133.3 (C2), $106.7\left(=\mathrm{CH}_{2}\right.$ ), 62.8 (C9a), 52.3 (C3), 52.1 (C5a), 48.7 (C9), 44.4 (C6), $41.8\left(\mathrm{CH}_{2}\right)$.
HRMS (ESI): $m / z[M+H]^{+}$calcd for $\mathrm{C}_{12} \mathrm{H}_{13} \mathrm{~N}_{2} \mathrm{OS}$ : 233.07431; found: 233.07431 .

$\left(5 \mathrm{a} S^{*}, 8 \mathrm{a} R^{*}\right)$-2-Methylene-2,3,6,7,8,8a-hexahydrocyclopenta[d]thiazolo[3,2-a]pyrimidin-5(5aH)-one (27)

Yield: $0.07 \mathrm{~g}(71 \%)$; light brown solid; $\mathrm{mp} 75-80^{\circ} \mathrm{C}$.

${ }^{1} \mathrm{H}$ NMR (500.20 MHz, $\left.\mathrm{CDCl}_{3}, 30^{\circ} \mathrm{C}\right): \delta=5.31\left(\mathrm{~s}, 1 \mathrm{H},=\mathrm{CH}_{2}\right), 5.20(\mathrm{~s}, 1$ $\left.\mathrm{H},=\mathrm{CH}_{2}\right), 4.59-4.75\left(\mathrm{~m}, 2 \mathrm{H}, \mathrm{H}_{2} \mathrm{C} 3\right), 4.17(\mathrm{q}, J=7.0 \mathrm{~Hz}, 1 \mathrm{H}, \mathrm{HC} 5 \mathrm{a}), 2.70$ (q, $J=8.1 \mathrm{~Hz}, 1 \mathrm{H}, \mathrm{HC} 8 \mathrm{a}), 2.05-2.22(\mathrm{~m}, 2 \mathrm{H}), 1.80-1.95$ (m, $2 \mathrm{H}), 1.56-$ $1.78(\mathrm{~m}, 2 \mathrm{H})$.

${ }^{13} \mathrm{C} \mathrm{NMR}\left(125.62 \mathrm{MHz}, \mathrm{CDCl}_{3}, 30{ }^{\circ} \mathrm{C}\right): \delta=169.4$ (C5), 153.1 (C9a), 133.7 (C2), $106.6\left(=\mathrm{CH}_{2}\right), 62.7$ (C8a), 52.3 (C3), 42.0 (C5a), 35.1 (C8), 29.7 (C6), 22.6 (C7).

HRMS (ESI): $m / z[\mathrm{M}+\mathrm{H}]^{+}$calcd for $\mathrm{C}_{10} \mathrm{H}_{13} \mathrm{~N}_{2} \mathrm{OS}$ : 209.06703; found: 209.07431.

$\left(1 S^{*}, 2 S^{*}\right)$-Ethyl 2-[(5-Methylenethiazolidin-2-ylidene)amino)]cyclopentanecarboxylate (28)

Yield: $0.10 \mathrm{~g}(78 \%)$; light brown solid; $\mathrm{mp} 54-55^{\circ} \mathrm{C}$.

${ }^{1} \mathrm{H}$ NMR $\left(500.20 \mathrm{MHz}, \mathrm{CDCl}_{3}, 30{ }^{\circ} \mathrm{C}\right): \delta=5.15\left(\mathrm{~s}, 1 \mathrm{H},=\mathrm{CH}_{2}\right), 5.10(\mathrm{~s}, 1$ $\left.\mathrm{H},=\mathrm{CH}_{2}\right), 4.66\left(\mathrm{~s}, 2 \mathrm{H}, \mathrm{H}_{2} \mathrm{C} 3\right), 4.11-4.21(\mathrm{~m}, 3 \mathrm{H}), 2.63(\mathrm{q}, J=7.1 \mathrm{~Hz}, 1$ $\mathrm{H}), 2.15-2.23(\mathrm{~m}, 1 \mathrm{H}), 1.97-2.05(\mathrm{~m}, 1 \mathrm{H}), 1.83-1.91(\mathrm{~m}, 1 \mathrm{H}), 1.70-$ $1.77\left(\mathrm{~m}, 2 \mathrm{H}, \mathrm{H}_{2} \mathrm{C}\right), 1.52-1.59(\mathrm{~m}, 1 \mathrm{H}), 1.25\left(\mathrm{t}, J=7.1 \mathrm{~Hz}, 3 \mathrm{H}, \mathrm{H}_{3} \mathrm{C}\right)$.

${ }^{13} \mathrm{C}$ NMR (125.62 MHz, $\left.\mathrm{CDCl}_{3}, 30{ }^{\circ} \mathrm{C}\right): \delta=174.6(\mathrm{CO}), 157.7\left(\mathrm{C2}^{\prime}\right), 148.5$ (C5'), $106.7\left(=\mathrm{CH}_{2}\right), 102.4\left(\mathrm{CH}_{2} \mathrm{CH}_{3}\right), 66.6\left(\mathrm{C}^{\prime}\right), 60.6(\mathrm{C} 2), 60.5(\mathrm{C} 1)$, 59.6 (C3), 51.0 (C5), 23.0 (C4), $14.2\left(\mathrm{CH}_{2} \mathrm{CH}_{3}\right)$.

HRMS (ESI): $m / z[\mathrm{M}+\mathrm{H}]^{+}$calcd for $\mathrm{C}_{12} \mathrm{H}_{19} \mathrm{~N}_{2} \mathrm{OS}$ : 255.11618; found: 255.11594 .

$\left(5 \mathrm{a} S^{*}, 10 \mathrm{a} R^{*}\right)$-2-Methylene-2,3,6,7,8,9,10,10a-octahydrocyclohepta[d]thiazolo[3,2-a]pyrimidin-5(5aH)-one (29)

Yield: $0.08 \mathrm{~g}$ (72\%); light brown solid; $\mathrm{mp} 102-104{ }^{\circ} \mathrm{C}$.

${ }^{1} \mathrm{H}$ NMR $\left(500.20 \mathrm{MHz}, \mathrm{CDCl}_{3}, 30{ }^{\circ} \mathrm{C}\right): \delta=5.30\left(\mathrm{~s}, 1 \mathrm{H},=\mathrm{CH}_{2}\right), 5.20(\mathrm{~s}, 1$ $\left.\mathrm{H},=\mathrm{CH}_{2}\right), 4.47-4.81\left(\mathrm{~m}, 2 \mathrm{H}, \mathrm{H}_{2} \mathrm{C} 3\right), 3.88-3.98$ (m, $\left.1 \mathrm{H}, \mathrm{HC} 5 \mathrm{a}\right), 2.61-$ 2.70 (m, $1 \mathrm{H}, \mathrm{HC} 11 \mathrm{a}), 1.38-1.97(\mathrm{~m}, 10 \mathrm{H})$.

${ }^{13} \mathrm{C}$ NMR (125.62 MHz, $\left.\mathrm{CDCl}_{3}, 30{ }^{\circ} \mathrm{C}\right): \delta=170.3$ (C5), 154.2 (C11a), 134.5 (C2), $106.6\left(=\mathrm{CH}_{2}\right), 59.7$ (C10a), 52.1 (C3), 44.5 (C5a), 32.3 (C10), 28.4 (C8), 26.1 (C6), 25.5 (C7), 23.3 (C9).

HRMS (ESI): $m / z[\mathrm{M}+\mathrm{H}]^{+}$calcd for $\mathrm{C}_{12} \mathrm{H}_{17} \mathrm{~N}_{2} \mathrm{OS}$ : 237.10561; found: 237.10549.

$\left(5 \mathrm{a} S^{*}, 11 \mathrm{a} R^{*}\right)-2-M e t h y l e n e-5 a, 6,7,8,9,10,11,11 \mathrm{a}-$ octahydro-2Hcycloocta[d]thiazolo[3,2-a]pyrimidin-5(3H)-one (30)

Yield: $0.08 \mathrm{~g}(70 \%)$; light brown solid; $\mathrm{mp} 77-80^{\circ} \mathrm{C}$.

${ }^{1} \mathrm{H}$ NMR $\left(500.20 \mathrm{MHz}, \mathrm{CDCl}_{3}, 30^{\circ} \mathrm{C}\right): \delta=5.29\left(\mathrm{~s}, 1 \mathrm{H},=\mathrm{CH}_{2}\right), 5.20(\mathrm{~s}, 1$ $\left.\mathrm{H},=\mathrm{CH}_{2}\right), 4.55-4.73$ (m, $\left.2 \mathrm{H}, \mathrm{H}_{2} \mathrm{C} 3\right), 3.79-3.87$ (m, $\left.1 \mathrm{H}, \mathrm{HC} 5 \mathrm{a}\right), 2.66-$ 2.76 (m, $1 \mathrm{H}, \mathrm{HC} 11 \mathrm{a}), 1.43-2.00(\mathrm{~m}, 12 \mathrm{H})$.

${ }^{13} \mathrm{C}$ NMR (125.62 MHz, $\left.\mathrm{CDCl}_{3}, 30{ }^{\circ} \mathrm{C}\right): \delta=171.1$ (C5), 154.8 (C12a), 134.7 (C2), $106.7\left(=\mathrm{CH}_{2}\right), 58.9$ (C11a), 52.0 (C3), 42.0 (C5a), 30.1 (C11), 26.8 (C6), 26.7 (C9), 25.5 (C8), 24.0 (C7), 23.8 (C10).

HRMS (ESI): $m / z[M+H]^{+}$calcd for $\mathrm{C}_{13} \mathrm{H}_{19} \mathrm{~N}_{2} \mathrm{OS}$ : 251.12126; found: 251.12113.

$\left(5 \mathrm{a} S^{*}, 11 \mathrm{aR}{ }^{*}\right)$-2-Methylene-5a,6,7,10,11,11a-hexahydro-2H-cycloocta[d]thiazolo[3,2-a]pyrimidin-5(3H)-one (31)

Yield: $0.10 \mathrm{~g}$ (80\%); light brown solid; $\mathrm{mp} 98-101^{\circ} \mathrm{C}$. 
${ }^{1} \mathrm{H}$ NMR $\left(500.20 \mathrm{MHz}, \mathrm{CDCl}_{3}, 30{ }^{\circ} \mathrm{C}\right): \delta=5.46-5.66(\mathrm{~m}, 2 \mathrm{H}, \mathrm{HC}=), 5.31$ $\left(\mathrm{s}, 1 \mathrm{H},=\mathrm{CH}_{2}\right), 5.21\left(\mathrm{~s}, 1 \mathrm{H},=\mathrm{CH}_{2}\right), 4.53-4.73\left(\mathrm{~m}, 2 \mathrm{H}, \mathrm{H}_{2} \mathrm{C} 3\right), 3.88-4.01$ (m, $1 \mathrm{H}, \mathrm{HC} 5 \mathrm{a}), 2.64-2.78(\mathrm{~m}, 1 \mathrm{H}, \mathrm{HC} 11 \mathrm{a}), 2.50-2.63\left(\mathrm{~m}, 1 \mathrm{H}, \mathrm{H}_{2} \mathrm{C}\right)$, 2.17-2.29 (m, $\left.1 \mathrm{H}, \mathrm{H}_{2} \mathrm{C}\right), 1.96-2.17$ ( $\left.\mathrm{m}, 4 \mathrm{H}, \mathrm{H}_{2} \mathrm{C}\right), 1.70-1.83$ ( $\mathrm{m}, 1 \mathrm{H}$, $\left.\mathrm{H}_{2} \mathrm{C}\right), 1.55\left(\mathrm{~s}, 1 \mathrm{H}, \mathrm{H}_{2} \mathrm{C}\right)$.

${ }^{13} \mathrm{C}$ NMR (125.62 MHz, $\left.\mathrm{CDCl}_{3}, 30{ }^{\circ} \mathrm{C}\right): \delta=171.2$ (C5), 155.2 (C12a), 134.7 (C2), 129.4 (C8), 126.7 (C9), $106.8\left(=\mathrm{CH}_{2}\right), 59.6(\mathrm{C} 3), 52.0$ (C11a), 41.5 (C5a), 30.3 (C11), 26.6 (C6), 25.9 (C7), 24.0 (C10).

HRMS (ESI): $m / z[M+H]^{+}$calcd for $\mathrm{C}_{13} \mathrm{H}_{17} \mathrm{~N}_{2} \mathrm{OS}: 249.10561$; found: 249.10563.

$\left(5 \mathrm{a} S^{*}, 10 \mathrm{~b} S^{*}\right)$-2-Methylene-2,3,5a,6-tetrahydroindeno[1,2-d]thiazolo[3,2-a]pyrimidin-5(10bH)-one (32)

Yield: $0.10 \mathrm{~g}$ (81\%); light brown solid; $\mathrm{mp} 101-102{ }^{\circ} \mathrm{C}$.

${ }^{1} \mathrm{H}$ NMR (500.20 MHz, $\left.\mathrm{CDCl}_{3}, 30{ }^{\circ} \mathrm{C}\right): \delta=7.46(\mathrm{~d}, J=5.1 \mathrm{~Hz}, 1 \mathrm{H}, \mathrm{Ar})$, 7.17-7.35 (m, $3 \mathrm{H}, \mathrm{Ar}$ ), 5.35 (d, $J=8.0 \mathrm{~Hz}, 1 \mathrm{H}, \mathrm{HC} 10 \mathrm{~b}$ ), 5.29 (s, $1 \mathrm{H}$, $\left.=\mathrm{CH}_{2}\right), 5.19\left(\mathrm{~s}, 1 \mathrm{H},=\mathrm{CH}_{2}\right), 4.70\left(\mathrm{~d}, J=15.8 \mathrm{~Hz}, 1 \mathrm{H}, \mathrm{H}_{2} \mathrm{C} 3\right), 4.60(\mathrm{~d}, J=$ $15.8 \mathrm{~Hz}, 1 \mathrm{H}, \mathrm{H}_{2} \mathrm{C} 3$ ), 3.46 (d, J = $\left.11.9 \mathrm{~Hz}, 1 \mathrm{H}, \mathrm{HC} 5 \mathrm{a}\right), 3.22-3.37$ (m, $2 \mathrm{H}$, $\left.\mathrm{H}_{2} \mathrm{C} 6\right)$.

${ }^{13} \mathrm{C}$ NMR (125.62 MHz, $\left.\mathrm{CDCl}_{3}, 30{ }^{\circ} \mathrm{C}\right): \delta=168.2$ (C5), 154.0 (C11a), 142.7 (C6a), 139.6 (C10a), 133.4 (C2), 128.2 (C9), 127.4 (C8), 124.6 (C7, C10), 106.7 (= $\mathrm{CH}_{2}$ ), 65.6 (C10b), 52.6 (C3), 41.8 (C5a), 35.1 (C6).

HRMS (ESI): $m / z[\mathrm{M}+\mathrm{H}]^{+}$calcd for $\mathrm{C}_{14} \mathrm{H}_{13} \mathrm{~N}_{2} \mathrm{OS}$ : 257.07431; found: 257.07458 .

\section{Retro-Diels-Alder Reaction}

2-Methylene-substituted methanothiazolo[2,3- $b]$ quinazolinone derivative 25 or 26 ( $0.5 \mathrm{mmol})$ was dissolved in a mixture of toluene/ $\mathrm{MeOH}(4: 1,5 \mathrm{~mL})$. The resulting solution was stirred at $140{ }^{\circ} \mathrm{C}$ under microwave irradiation for $30 \mathrm{~min}$. The solvent was then evaporated and product 33 was filtered from $\mathrm{Et}_{2} \mathrm{O}$.

\section{Retro-Diels-Alder Reaction with Norbornene Propargyl Deriva- tives; One-Pot Procedure}

$N$-Propargyl-substituted amino amide base $7 \mathbf{c}$ or $\mathbf{8 c}(0.5 \mathrm{mmol})$ was dissolved in toluene/MeOH $(4: 1,10 \mathrm{~mL})$ followed by the addition of $\mathrm{KOH}(0.5 \mathrm{mmol})$ and $\mathrm{CS}_{2}(1 \mathrm{mmol})$. The reaction mixture was stirred at two different temperature barriers under microwave irradiation. First at $90{ }^{\circ} \mathrm{C}$ for $15 \mathrm{~min}$ and then at $140{ }^{\circ} \mathrm{C}$ for $30 \mathrm{~min}$. The solvent and residual $\mathrm{CS}_{2}$ were evaporated and the residue was dissolved in water $(5 \mathrm{~mL})$ and extracted with $\mathrm{CH}_{2} \mathrm{Cl}_{2}(3 \times 10 \mathrm{~mL})$. The combined organic phase was dried and evaporated. The desired product 33 was crystallised using $\mathrm{Et}_{2} \mathrm{O}$.

\section{Retro-Diels-Alder Reaction with Norbornene Isothiocyanate De- rivatives; One-Pot Procedure}

Norbornene ethyl 2-isothiocyanatocarboxylate 11b or 12b (0.5 $\mathrm{mmol}$ ) was dissolved in toluene/MeOH $(4: 1,10 \mathrm{~mL})$ followed by the addition of $\mathrm{K}_{2} \mathrm{CO}_{3}(0.5 \mathrm{mmol})$ and propargylamine $(0.5 \mathrm{mmol})$. The reaction mixture was stirred at two different temperature barriers under microwave irradiation. First at $90^{\circ} \mathrm{C}$ for $15 \mathrm{~min}$ and then at $140{ }^{\circ} \mathrm{C}$ for $30 \mathrm{~min}$. After evaporation of the solvent, the product was purified by column chromatography with EtOAc as eluent. The desired product 33 was crystallised using $\mathrm{Et}_{2} \mathrm{O}$.

2-Methylene-2H-thiazolo[3,2-a]pyrimidin-5(3H)-one (33) Yield: $0.08 \mathrm{~g}$ (98\%); light brown solid; $\mathrm{mp} 145-146{ }^{\circ} \mathrm{C}$.
${ }^{1} \mathrm{H}$ NMR $\left(500.20 \mathrm{MHz}, \mathrm{CDCl}_{3}, 30^{\circ} \mathrm{C}\right): \delta=7.74(\mathrm{~d}, 1 \mathrm{H}, J=6.6 \mathrm{~Hz}, \mathrm{HC} 6)$, $6.17(\mathrm{~d}, 1 \mathrm{H}, J=6.6 \mathrm{~Hz}, \mathrm{HC}$ ), $5.47(\mathrm{~d}, 1 \mathrm{H}, J=2.5 \mathrm{~Hz},=\mathrm{CH}), 5.35(\mathrm{~d}, 1 \mathrm{H}$, $J=2.5 \mathrm{~Hz},=\mathrm{CH}), 5.05\left(\mathrm{t}, 2 \mathrm{H}, J=2.5 \mathrm{~Hz}, \mathrm{H}_{2} \mathrm{C} 3\right)$.

${ }^{13} \mathrm{C}$ NMR (125.62 MHz, $\left.\mathrm{CDCl}_{3}, 30{ }^{\circ} \mathrm{C}\right): \delta=163.9(\mathrm{C} 5), 160.0$ (C8a), 153.8 (C7), 132.5 (C2), 110.9 (C6), $108.7\left(=\mathrm{CH}_{2}\right), 54.7$ (C3).

HRMS (ESI): $m / z[M+\mathrm{H}]^{+}$calcd for $\mathrm{C}_{7} \mathrm{H}_{7} \mathrm{~N}_{2} \mathrm{OS}$ : 167.02736; found: 167.02741 .

\section{Determination of the Antiproliferative Activities}

The growth-inhibitory effects of the presented quinazolinone analogues were determined by a standard MTT [3-(4,5-dimethylthiazol2-yl)-2,5-diphenyltetrazolium bromide] assay against four human cancer cell lines (cervical cancer HeLa, breast cancers MCF-7 and MDA-MB-231 and ovarian cancer A2780). The murine fibroblast $\mathrm{NIH} / 3 \mathrm{~T} 3$ cell line was additionally included to obtain data related to the cancer selectivity of the tested compounds. All cell lines were purchased from the European Collection of Cell Cultures (Salisbury, UK). The cells were cultivated in Eagle's minimal essential medium supplemented with $10 \%$ fetal bovine serum, $1 \%$ non-essential amino acids, and $1 \%$ Antibiotic-Antimycotic complex (penicillin, streptomycin, amphotericin $\mathrm{B}$ ) at $37^{\circ} \mathrm{C}$ in a humidified atmosphere containing $5 \% \mathrm{CO}_{2}$. All media and supplements were purchased from Lonza Group Ltd., (Basel, Switzerland). Cancer cells were seeded into 96-well plates (5000 cells/well) after an overnight incubation, and the test compounds were added at two different concentrations $(10 \mu \mathrm{M}$ and 30 $\mu \mathrm{M})$ and incubated for another 72 hours under cell-culturing conditions. Finally, $20 \mu \mathrm{L}$ of $5 \mathrm{mg} / \mathrm{mL}$ MTT solution was added to each well and the contents were incubated for a further 4 hours. The medium was removed, and the precipitated formazan crystals were dissolved in DMSO by shaking at $37{ }^{\circ} \mathrm{C}$ for 60 minutes. The absorbance was measured at $545 \mathrm{~nm}$ by using a microplate reader (SPECTROStar Nano, BMG Labtech). Cisplatin (Ebewe GmbH, Unterach, Austria), an extensively applied anticancer agent, was used as a reference agent. ${ }^{27}$

\section{Conflict of Interest}

The authors declare no conflict of interest.

\section{Funding Information}

We are grateful to the Hungarian Scientific Research Fund (OTKA No. K 138871). Financial support from the University of Szeged (GINOP2.3.2-15-2016-00038 project) and Ministry of Human Capacities, Hungary (20391-3/2018/FEKUSTRAT) is acknowledged.

\section{Supporting Information}

Supporting information for this article is available online at https://doi.org/10.1055/s-0040-1720028.

\section{References}

(1) Li, H.; Huang, R.; Qiu, D.; Yang, Z.; Liu, X.; Ma, J.; Ma, Z. Prog. Nat. Sci. 1998, 8, 359.

(2) Alagarsamy, V.; Solomon, V. R.; Dhanabal, K. Bioorg. Med. Chem. 2017, 15, 235.

(3) Baba, A.; Kawamura, N.; Makino, H.; Ohta, Y.; Taketomi, S.; Sohda, T. J. Med. Chem. 1996, 39, 5176. 
(4) Lakhan, R.; Singh, O. P.; Singh, J. R. L. J. Indian Chem. Soc. 1987, $64,316$.

(5) Chen, X.; Du, Y.; Sun, H.; Wang, F.; Kong, L.; Sun, M. Bioorg. Med. Chem. Lett. 2014, 24, 884.

(6) Jeminejs, A.; Goliškina, S. M.; Novosjolova, I.; Stepanovs, D.; Bizdēna, E.; Turks, M. Synthesis 2021, 53, 1443.

(7) Buha, V. M.; Rana, D. N.; Chhabria, M. T.; Chikhalia, K. H.; Mahajan, B. M.; Brahmkshatriya, P. S.; Shah, N. K. Med. Chem. Res. 2013, 22, 4096.

(8) Wan, Z.; Hu, D.; Li, P.; Xie, D.; Gan, X. Molecules 2015, 20, 11861.

(9) Al-Omary, F. A. M.; Hassan, G. S.; El-Messery, S. M.; Nagi, M. N.; Habib, E. S. E.; El-Subbagh, H. I. Eur. J. Med. Chem. 2013, 63, 33.

(10) Antypenko, O. M.; Kovalenko, S. I.; Karpenko, O. V.; Nikitin, V. O.; Antypenko, L. M. Helv. Chim. Acta 2016, 99, 621.

(11) Li, W.; Wang, X. Y.; Zheng, R.; Yan, H.; Cao, Z.; Zhong, L.; Wang, Z. R.; Ji, P.; Yang, L. L.; Wang, L. J.; Xu, Y.; Liu, J. J.; Yang, J.; Zhang, C. H.; Ma, S.; Feng, S.; Sun, Q. Z.; Wei, Y. Q.; Yang, S. Y. J. Med. Chem. 2012, 55, 3852.

(12) Liu, G.; Liu, C. P.; Ji, C. N.; Sun, L.; Wen, Q.; Chin, W.J. Org. Chem. 2008, 28, 525

(13) Liu, F.; Huang, Y. Pestic. Biochem. Physiol. 2011, 101, 248.

(14) (a) Kühler, T. C.; Fryklund, J.; Bergman, N. K.; Weilitz, J.; Lee, A.; Larsson, H. J. Med. Chem. 1995, 38, 4906. (b) Llauger, L.; He, H. Z.; Kim, J.; Aguirre, J.; Rosen, Z.; Peters, U.; Davies, P.; Chiosis, G. J. Med. Chem. 2005, 48, 2892. (c) Mavrova, A. T.; Vuchev, D.; Anichina, K.; Vassilev, N. Eur. J. Med. Chem. 2010, 45, 5856.

(15) (a) Thari, F. Z.; Tachallait, H.; El Alaoui, N. E.; Talha, A.; Arshad, S.; Álvarez, E.; Karrouchi, K.; Bougrin, K. Ultrason. Sonochem. 2020, 68, 105222. (b) Li, W.; Lu, Y.; Wang, Z.; Dalton, J. T.; Miller, D. D. Bioorg. Med. Chem. Lett. 2017, 17, 4113. (c) Dheur, J.;
Ollivier, N.; Melnyk, O. Org. Lett. 2011, 13, 1560. (d) Mann, G.; Satish, G.; Meledin, R.; Vamisetti, G. B.; Brik, A. Angew. Chem. Int. Ed. 2019, 58, 13540.

(16) Orysyk, V. V.; Zborovskii, Y. L.; Staninets, V. I.; Dobosh, A. A.; Khripak, S. M. Chem. Heterocycl. Compd. 2003, 39, 640.

(17) (a) Ghorab, M. M.; Abdel-Gawad, S. M.; El-Gaby, M. S. Farmaco 2000, 55, 249. (b) Janardhan, B.; Manjulatha, K.; Srinivas, B.; Rajitha, B.; Muralikrishna, N.; Sadanandam, A. RSC Adv. 2014, 4, 22866.

(18) (a) Pellón, R. F.; Docampo, M. L.; Fascio, M. L. Synth. Commun. 2007, 37, 1853. (b) Bleda, J. A.; Fresneda, P. M.; Orenes, R.; Molina, P. Eur. J. Org. Chem. 2009, 15, 2490. (c) Wang, P.; Tang, S.; Lei, A. Green Chem. 2017, 19, 2092. (d) Zhou, H.; Chen, W.; Chen, Z. Org. Lett. 2018, 20, 2590. (e) Tan, J.; Wang, Z.; Yuan, J.; Peng, Y.; Chen, Z. Adv. Synth. Catal. 2019, 361, 1295.

(19) Mahdavi, M.; Bialam, M.; Saeedi, M.; Jafarpour, F.; Foroumadi, A.; Shafiee, A. Synlett 2015, 26, 173.

(20) Miao, J.; Sang, X.; Wang, Y.; Deng, S.; Hao, W. Org. Biomol. Chem. 2019, 17, 6994.

(21) Palkó, M.; El Haimer, M.; Kormányos, Z.; Fülöp, F. Molecules 2019, 24, 772.

(22) El Haimer, M.; Palkó, M.; Haukka, M.; Gajdács, M.; Zupkó, I.; Fülöp, F. RSC Adv. 2021, 11, 6952.

(23) Urleb, U.; Neidlein, R.; Kramer, W. Helv. Chim. Acta 1993, 76, 431.

(24) Stajer, G.; Szabo, A. E.; Sohar, P. Heterocycles 1999, 1849.

(25) Palkó, M.; Evanics, F.; Bernáth, G.; Fülöp, F. J. Heterocycl. Chem. 2000, 37, 779 .

(26) Szakonyi, Z.; Fülöp, F.; Bernáth, G.; Sohár, P. Heterocycles 1996, 2,625 .

(27) Mosmann, T. J. Immunol. Methods 1983, 65, 55. 